\title{
Earth-Life Transitions:
}

Paleobiology in the Context of Earth System Evolution

Table of Contents

Earth-Life Transitions: Paleobiology in the Context of Earth System Evolution-Forward

P. David Polly, Jason J. Head, and David L. Fox..

A Quantitative Model for Distinguishing Between Climate Change, Human Impact, and Their Synergistic Interaction as Drivers of the Late Quaternary Megafaunal Extinctions

Charles R. Marshall, Emily L. Lindsey, Natalia A. Villavicencio, and Anthony D. Barnosky...

Measuring Earth-Life Transitions: Ecometric Analysis of Functional Traits from Late Cenozoic Vertebrates

P. David Polly and Jason J. Head.

Late Proterozoic Transitions in Climate, Oxygen, and Tectonics, and the Rise of Complex Life

Noah J. Planavsky, Lidya G. Tarhan, Eric J. Bellefroid, David A. D. Evans, Christopher T. Reinhard,

Gordon D. Love, and Timothy W. Lyons.

Reconstructing the Dust Cycle in Deep Time: the Case of the Late Paleozoic Icehouse

Gerilyn S. Soreghan, Nicholas G. Heavens, Linda A. Hinnov, Sarah M. Aciego, and Carl Simpson.

Marine Ecological State-Shifts Following the Triassic-Jurassic Mass Extinction

Kathleen A. Ritterbush, Yadira Ibarra, David J. Bottjer, Frank A. Corsetti, Silvia Rosas, A. Joshua West,

William M. Berelson, and Joyce Ann Yager.

Integrating Paleobotanical, Paleosol, and Stratigraphic Data to Study Critical Transitions: A Case Study From

The Late Cretaceous-Paleocene Of India

Selena Y. Smith, Steven R. Manchester, Bandana Samant, Dhananjay M. Mohabey, Elizabeth Wheeler, Pieter Baas,

Dashrath Kapgate, Rashmi Srivastava, and Nathan D. Sheldon.

Reconstructing Extinct Plant Water Use for Understanding Vegetation-Climate Feedbacks: Methods, Synthesis, and a

Case Study Using the Paleozoic-Era Medullosan Seed Ferns

Jonathan P. Wilson, Joseph D. White, William A. DiMichele, Michael T. Hren, Christopher J.

Poulson, Jennifer C. McElwain, and Isabel P. Montañez.

Biotic and Abiotic Forcing During the Transition to Modern Grassland Ecosystems: Evolutionary and Ecological Responses of

Small Mammal Communities Over the Last 5 Million Years

David L. Fox, Robert A. Martin, Elizabeth Roepke, Anne C. Fetrow, Brendan Fischer-Femal, Kevin T. Uno,

Kena Fox-Dobbs, Kathryn E. Snell, Andrew Havales, and Pratigya J. Possilar. 